\title{
DEscentralización Y RECENTRALIZACIÓN DEL PODER EN COLOMBIA. LA BÚSQUEDA DE EQUILIBRIOS ENTRE LA NACIÓN Y LAS ENTIDADES TERRITORIALES
}

\author{
Decentralization AND Re- \\ Centralization of Power in Colombia. \\ The Search for a Balance between \\ the Nation and Territorial Agencies
}

DEsCENTRALIZAÇÃo E RECENTRALIZAÇÃo DO PODER NA ColÔMBIA. A BUSCA DE EQUILÍBRIOS ENTRE A NAÇÃO E AS ENTIDADES TERRITORIAIS

DIANA CAROLINA VALENCIA-TELLO* VERA KARAM DE CHUEIRI**

\footnotetext{
* Profesora e Investigadora, Universidad Federal del Paraná (Brasil). dianacvt@hotmail.com

** Profesora e Investigadora de Derecho Constitucional, Universidad Federal del Paraná (Brasil). vkchueiri@uol.com.br
}

RECIBIDO: 9 DE SEPTIEMBRE DE 2013. ENVío A PARES: 18 DE SEPTIEMBRE DE 2013. APROBADO POR PARES: 18 DE NOVIEMBRE DE 2013. ACEPTADO: 13 DE DICIEMBRE DE 2013

DOI: $10.5294 / D I K A .2014 .23 .1 .7$ 


\section{RESUMEN}

El modelo de Estado unitario y centralista ha sido el modelo preferido de gobierno en Colombia desde la Constitución de 1886. Esto explica en parte, las dificultades que desde un inicio tuvo el Estado para descentralizar su poder. En nuestro concepto, el proceso de descentralización iniciado en la decada de los años ochenta, obedeció, principalmente a dos situaciones contradictorias. Primero, en teoría, la descentralización buscó dar una respuesta a las comunidades sobre la crisis de legitimidad del Estado, pues gran parte de la población no se sentía representada por el gobierno nacional. Pero, en la practica, el proceso de descentralización obedeció a una estrategia del gobierno nacional para formalizar el discurso de la descentralización, retirando con esto presiones politicas indeseadas, sin que existieran politicas o mecanismos efectivos para otorgar a las entidades territoriales mayor poder de decisión o de gestión.

\section{PALABRAS CLAVE:}

Descentralización territorial, centralización del poder, autonomía territorial, ordenamiento territorial, organización político administrativa. 


\section{ABSTRACT}

A unitary and centralized state has been the preferred model of government in Colombia since the Constitution of 1886 . This partly explains the difficulties encountered by the state from the beginning in terms of decentralizing its power. The authors believe the decentralization process that began in the 1980s was mainly the result of two conflicting situations. To begin with, decentralization was an attempt, in theory, to respond to the community on the crisis of legitimacy of the state, since a large portion of the Colombian population did not feel represented by the national government. However, in practice, the decentralization process was a strategy the national government used to formalize the discourse on decentralization, so as to relieve unwanted political pressure in this respect. Yet, in fact, there were no policies or effective mechanisms to give local authorities greater power for decision-making or management.

\section{KEY WORDS:}

Territorial decentralization, centralization of power, territorial autonomy, zoning, political and administrative organization. 


\section{RESUMO}

O modelo de Estado unitário e centralista tem sido o modelo de governo preferido na Colômbia desde a Constituição de 1886. Isso explica, em parte, as dificuldades que, desde o começo, o Estado teve para descentralizar seu poder. Em nosso conceito, o processo de descentralização iniciado na década de 1980 obedeceu, principalmente, a duas situações contraditórias. Primeiramente, em teoria, a descentralização buscou dar uma resposta às comunidades sobre a crise de legitimidade do Estado, uma vez que grande parte da população não se sentia representada pelo governo nacional. Porém, na prática, o processo de descentralização obedeceu a uma estratégia do governo nacional para formalizar o discurso da descentralização, retirando com isso pressões politicas indesejadas, sem que existissem políticas ou mecanismos efetivos para outorgar às entidades territoriais maior poder de decisão ou de gestão.

\section{PALAVRAS-CHAVE:}

Descentralização territorial, centralização do poder, autonomia territorial, ordenamento territorial, organização político-administrativa. 
SUMARIO: INTRODUCCIÓN; 1. EL CONCEPTO DE NACIÓN, LA CRISIS DE LOS AÑOS OCHENTA Y LA DESCENTRALIZACIÓN DEL PODER; 2. CENTRALIZACIÓN DEL PODER DEL ESTADO EN EL PODER EJECUTIVO; 3. LA DESCENTRALIZACIÓN TERRITORIAL EN LA DÉCADA DE LOS OCHENTA;

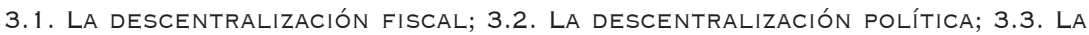
DESCENTRALIZACIÓN ADMINISTRATIVA; 4. TRANSFORMACIONES EN LA ESTRUCTURA DE LA NACIÓN EN LA DÉCADA DE LOS OCHENTA; 5. PRINCIPALES CARACTERÍSTICAS DE LA DESCENTRALIZACIÓN TERRITORIAL EN COLOMBIA; 6. CONCLUSIONES; BIBLIOGRAFía.

\section{INTRODUCCIÓN}

Históricamente, Colombia ha sido un país caracterizado por la centralización del poder político, administrativo y fiscal en la nación, y solo hasta la década de los ochenta inició un proceso serio de descentralización territorial otorgando mayor autonomía y recursos a las entidades territoriales mediante la implementación de diferentes reformas constitucionales, legales y reglamentarias. Aún así, desde el inicio, el proceso de descentralización se caracterizó por falta de planeación, de capacitación y claridad sobre las normas y las competencias aplicables en los diferentes sectores de Gobierno de los niveles nacional y territorial.

Esto en parte debido a que la descentralización territorial en Colombia se ha construido mediante la promulgación de leyes y decretos del orden nacional que otorgan mayor autonomía a las entidades territoriales, sin tener en cuenta las características particulares que marcan la diferencia, tales como el tamaño, el tipo de población, las actividades económicas relevantes, el nivel de desarrollo social, político y económico, etc.

La legislación nacional, al homogeneizar a las entidades territoriales, entregó de forma automática, de un día para otro, competencias que estuvieron a cargo de la nación por más de un siglo, sin verificar antes la capacidad real de gestión de las entidades y sin contar con periodos de transición que otorgaran tiempo a los funcionarios responsables para entrenarse y asumir de manera responsable las nuevas competencias otorgadas por las leyes nacionales.

De esta forma, la descentralización territorial se ha construido de arriba hacia abajo mediante la promulgación de leyes de aplicación inmediata. En este orden de ideas, el presente artículo busca llamar la atención sobre las deficiencias presentadas desde el inicio del proceso, con la finalidad de comprender las razones que han impedido una efectiva descentralización del poder en Colombia desde la década de los ochenta.

En nuestro concepto, el proceso de descentralización obedeció, en la teoría, a dar una respuesta a las comunidades sobre la crisis de legitimidad del Estado, pues gran parte de la población no se sentía representada por el Gobierno nacional. Pero, en la práctica, el proceso de descentralización se debió a una estrategia del Gobierno nacional para formalizar el discurso de la descentralización, retirando con esto presiones políticas indeseadas, sin que existieran políticas o mecanismos efectivos para otorgar mayor poder de decisión o de gestión a las entidades 
territoriales, en cuanto el Gobierno central continuaba controlando el proceso de planeación y la mayor parte del presupuesto nacional.

Para desarrollar mejor estas ideas, a continuación analizaremos el concepto de nación, la crisis de los años ochenta y la descentralización del poder, para después analizar aspectos puntuales sobre la estructura centralizada del Estado colombiano. Después estudiaremos el proceso de descentralización fiscal, administrativa y politica de los años ochenta, para seguidamente estudiar las transformaciones que se realizaron sobre el orden nacional en la misma época. Por último, se analizará el marco teórico que caracterizó la descentralización territorial en Colombia, para así explicar cómo el modelo de Estado unitario y centralista ha sido el preferido del Gobierno en Colombia, desde la Constitución de 1886.

\section{EL CONCEPTO DE NACIÓN, LA CRISIS DE LOS AÑOS OCHENTA Y LA DESCENTRALIZACIÓN DEL PODER}

El concepto de nación fue un subproducto de las revoluciones liberales europeas, que buscaba vincular jurídica y politicamente al conjunto de individuos que están unidos al Estado, lo que a su vez permitió centralizar el poder de mando y control, ya que el Estado es la representación suprema de la "voluntad general" de la nación ${ }^{1}$. Al respecto, Rodríguez afirma: "La nación, como concepto político, con las premisas del Estado-nación, es una construcción meramente instrumental que busca justificar y legitimar la existencia del Estado, Sieyes la definió como "un cuerpo de asociados que viven sujetos a una ley común y representados por la misma legislatura"2.

Para los liberales del siglo XIX, la nación ya no era sujeto de poder constituyente; la nación era una realidad histórico-natural, que no se determinaba por la voluntad de los individuos y no definía de manera contractual las características de las instituciones políticas: la nación como sus instituciones eran producto de la historia. La nación se definía sobre la base histórica, como sucesión concatenada de generaciones, cada una de las cuales estaba obligada a tener en cuenta la herencia de las generaciones precedentes y, por esto, no es posible decidir todo contractual y voluntariamente de nuevo. Las instituciones son fruto de la historia y de la experiencia de una nación, por esto no son ilimitadamente modificables ${ }^{3}$. Colombia, acorde con las tendencias europeas del Estado liberal, proclamó la Constitución de 1886 con base en el concepto de nación, esto es, con base en la idea de la existencia de una unidad nacional homogénea, que permitía

1 Diana Carolina Valencia Tello, El Estado en la era de la globalización y las nuevas tecnologías. Tesis de Doctorado, Universidad Federal del Paraná, Brasil, 2013.

2 Miguel Caminal, "Nacionalismo y federalismo", en Joan Antón Mellón (ed.), Ideologías y movimientos políticos contemporáneos, Madrid, Tecnos, 1998, p. 93; María Luisa Rodríguez Peñaranda, Minorías, acción pública de inconstitucionalidad y democracia deliberativa, Bogotá, Universidad Externado de Colombia, 2005, p. 67.

3 Maurizio Fioravanti, Los derechos fundamentales: apuntes de historia de las constituciones, Madrid, Trotta, 2007, pp. 104-105. 
establecer claramente el interés general, mediante la promulgación y aplicación de leyes generales, aunque la heterogeneidad de la raza, la cultura y las regiones del país fuera la regla.

Así, por un poco más de un siglo de vigencia de la Constitución de 1886, se buscó construir la identidad de la nación o, mejor, se buscó la unidad nacional mediante la promulgación de leyes generales de "obligatorio" cumplimiento en todo el territorio nacional, pasando por alto la diversidad existente, tal y como lo describe RoDRíGUEZ:

"En la edificación de este proyecto [de unidad nacional] se pasó por alto, o posiblemente se subestimó, que en Colombia se combinaban de manera entrelazada diferentes variantes, que convertían este territorio en un hervidero de diferencias étnicas, identidades, culturas y tradiciones, en un contexto donde la geografía colabora para que estas diferencias gocen de su propio territorio y precisas fronteras naturales"4.

En la década de los ochenta y noventa, cuando alrededor del mundo es evidente que el Estado-nación no puede continuar respondiendo simultáneamente a las diversas demandas de la población, debido al surgimiento de diversas identidades e intereses en todos los países, existe una marcada tendencia en los gobiernos nacionales o federales a descentralizar algo de su poder en las instituciones políticas locales y regionales para tratar de superar la crisis. Según CASTELLS, este movimiento ocasiona dos tendencias convergentes,

"...[p]or una parte, debido a la diferenciación territorial de las instituciones estatales, las identidades de las minorías regionales y nacionales encuentran su expresión más fácil en los ámbitos local y regional. Por otra parte, los gobiernos nacionales tienden a centrarse en controlar los desafios estratégicos planteados por la globalización de la salud, la comunicación y el poder, dejando, por lo tanto, que niveles inferiores de gobierno asuman la responsabilidad de vincularse con la sociedad en la gestión de los asuntos de la vida cotidiana, para reconstruir la legitimidad mediante la descentralización ${ }^{5 "}$.

Para HeRnández-Bonivento, en América Latina las causas para la reforma al Estado y la descentralización son diversas y van desde la presión de organismos internacionales hasta el surgimiento de movimientos sociales de corte democrático, pero también se puede encontrar explicación en las políticas neoliberales, los modelos de desarrollo endógenos y los cambios en las dinámicas de poder de los partidos politicos ${ }^{6}$.

En concreto, el proceso de descentralización en América Latina obedeció a razones económicas, políticas y administrativas. Desde la perspectiva económica,

4 María Luisa Rodríguez Peñaranda, Minorias, acción pública..., op. cit., p. 68.

5 Manuel CASTElls, La era de la información. Economía sociedad y cultura, vol. II. El poder de la identidad, 5 ed., México, Siglo XXI Editores, trad. Carmen Martínez Gimeno, 2004, p. 301.

6 José A. Hernández-Bonivento, Instituciones informales y reforma del Estado: análisis al proceso de descentralización en Colombia, Madrid, GIGAPP Estudios/Working Papers, 2012. 
la descentralización trató de responder a la crisis del modelo de Estado desarrollista, que centralizaba en el Poder Ejecutivo las decisiones sobre el desarrollo territorial; así como también centralizaba la prestación de los servicios públicos básicos, sin tener en cuenta las grandes diferencias existentes entre los territorios y las poblaciones. Las presiones fiscales dieron un argumento adicional para buscar que los gobiernos locales pudieran administrar su propio presupuesto, buscando mayor capacidad de recaudo y mejor asignación del gasto, con base en las necesidades identificadas por dichos gobiernos ${ }^{7}$. Evidentemente, la crisis fiscal de los Estados en la década de los ochenta no ayudó a garantizar los recursos necesarios para otorgar en la práctica mayor autonomía a los gobiernos locales.

Como razones políticas Hernández-Bonivento señala que en 1976, en América Latina existian solo tres países que contaban con votaciones periódicas para la elección de representantes a nivel nacional, por tanto, la descentralización política buscó profundizar la democracia en la región para, al mismo tiempo, superar los problemas de legitimación de la acción gubernamental. Este cambio permitió que en la actualidad (con la sola excepción de los intendentes chilenos), en todos los países de Suramérica se elijan los representantes territoriales de manera democrática ${ }^{8}$. Finalmente, con relación a las razones administrativas, la descentralización buscó acercar la administración pública a la ciudadanía, otorgando mayores competencias a los gobiernos locales para decidir sobre la elaboración, implementación y evaluación de las políticas públicas de manera más eficaz, económica y eficiente. En los ochenta, se consideraba que los gobiernos locales tenían más acceso a información relevante para establecer y priorizar los objetivos de la acción pública, así como también mejores y mayores posibilidades de implementación y evaluación de las politicas públicas.

De esta forma, el proceso de descentralización que se inició en Colombia en la década de los ochenta, fue parte de una tendencia mundial y regional para fortalecer la acción local, otorgando mayores competencias y recursos a las autoridades locales, desde el Gobierno central. Para analizar la forma como se dio el proceso de descentralización en Colombia, y evidenciar las dificultades presentadas, primero es necesario analizar cómo se encontraba centralizado el poder, conforme la Constitución de 1886.

7 P. LINDERT, y O. VERKoREn, Decentralized development in Latin America: experiences in local governance and local development, New York, Springer, 2010; M. Gundle, Going Local. Decentralization, democratization and the promise of good governance, Princeton, Pricenton University Press, 2007; T. G. FAllet, Decentralization and subnational politics in Latin America, New York, Cambridge University Press, 2010; I. Finot, Descentralización en América Latina: Teoría y práctica, Santiago de Chile, Cepal, 2001; en José A. HernándeZ-Bonivento, op. cit.

8 M. Salvador Crespo, "El fortalecimiento institucional de los municipios", en Castillo Blanco, Análisis de los procesos de descentralización en América Latina: balances y perspectivas, Granada, Unión Iberoamericana de Municipalistas, 2008; T. G. FALLETI, Decentralization and subnational politics in Latin America, op. cit.; E. CABrero Mendoza, La nueva gestión municipal en México: análisis de experiencias innovadoras en gobiernos locales, México, CIDE, 1995, en José A. Hernández-Bonivento, op. cit. 


\section{Centralización del poder del Estado en el PODER EJECUTIVO}

De acuerdo con la Constitución de 1886, Colombia se definía como una república unitaria con "centralización política y descentralización administrativa", cuyas entidades territoriales eran las comisarias, intendencias, departamentos y municipios. Desde sus inicios, la Constitución de 1886 se caracterizó por concentrar excesivamente el poder en el nivel central de Gobierno en cabeza del presidente, quien tenía un periodo presidencial de seis años, con posibilidad de reelección y con potestad de nombramiento y separación libre de los ministros del despacho, los agentes diplomáticos, los gobernadores, magistrados de la Corte Suprema de Justicia, funcionarios del Ministerio Público, dos consejeros de Estado y los magistrados de los tribunales superiores. Adicionalmente, tenía amplias potestades para declarar el estado de sitio, y entre las disposiciones transitorias se encontraba la de prevenir y reprimir los abusos de la prensa ${ }^{9}$.

Evidentemente, la estructura institucional del Estado colombiano otorgaba total poder político, administrativo y fiscal al presidente dentro del territorio nacional, ya que este tenía la potestad de nombrar autónomamente a los gobernadores en los departamentos, impidiendo así toda participación o control político de los ciudadanos sobre los gobernantes en los respectivos territorios. Igualmente, los gobernadores nombraban y retiraban libremente a los alcaldes de los municipios.

Un estudio de Mauricio CÁRDEnAs et al, sobre política económica de Colombia, afirma que desde mediados del siglo XIX, el Ministerio de Hacienda y Crédito Público fue la suprema autoridad presupuestal del país, limitando el papel del Congreso en la aprobación del presupuesto y otorgando un papel protagónico al Poder Ejecutivo sobre la disposición de los recursos del Estado. La Ley 34 de 1923, eliminó la capacidad que tenía el Congreso de incrementar unilateralmente el presupuesto y estableció que cualquier adición debía contar con la aprobación del Ejecutivo. El incremento del poder decisorio sobre el presupuesto se consolidó con la creación de la Dirección de Presupuesto del Ministerio de Hacienda mediante el Decreto 164 de 1950 y, posteriormente, con la creación del Departamento Nacional de Planeación (DNP) en $1964^{10}$.

La reforma constitucional de 1968 robusteció aún más el poder central en cabeza del Ejecutivo, otorgando mayores facultades para declarar la emergencia económica y social, pudiendo dictar decretos con fuerza de ley, nombrar y remover libremente a los directores y gerentes de establecimientos públicos nacionales, incluidos los rectores de las universidades públicas, y disponer de la iniciativa exclusiva para la formulación de políticas relacionadas con la planeación y el gasto público, e intervenir sin sujeción a la ley ordinaria en el banco de emisión y en las

9 Javier Henao Hidron, El poder municipal, 16 ed., Medellin, Biblioteca Juridica, 2013, p. 65.

10 Mauricio CÁrdenas, Carolina MejíA, Mauricio Olivera, La economía politica del proceso presupuestal: el caso de Colombia, Bogotá, BID-Fedesarrollo, 2007, en http://idbdocs.iadb.org/wsdocs/getdocument.aspx?docnum=1161524. Fecha de Consulta: 17 de septiembre de 2012. 
actividades de intermediación financiera ${ }^{11}$. En este contexto, el poder político de la nación centralizó varias competencias que antes pertenecían a los departamentos y municipios, tal y como lo describe Escobar:

"Les quitamos [a las entidades territoriales] la policía, la educación, en buena parte la salud, el manejo de catastro y hasta la fijación de rutas de los buses urbanos y congelamos sus recursos en tal forma que dificilmente pueden seguir siquiera el ritmo de la inflación crónica para tratar de cubrir sus gastos de funcionamiento ${ }^{12 "}$.

En la década de los sesenta, en desarrollo de la tendencia mundial de mayor intervención del Estado, la reforma de 1968 institucionalizó como responsabilidad del Estado "la dirección general de la economía", la cual tenía por finalidad la racionalización y planificación de las actividades económicas, el logro del pleno empleo y la administración de los recursos naturales, para obtener la justicia social y el desarrollo integral de la comunidad. Para lo anterior, la reforma dejó al Congreso la potestad de determinar la estructura de la administración pública, el estatuto de carrera administrativa y la fijación del régimen salarial y prestacional de los empleados públicos. Adicionalmente, se elevaron a canon constitucional las nociones de establecimientos públicos, empresas industriales y comerciales del Estado y sociedades de economía mixta. La reforma definió a los departamentos, los municipios, las intendencias y comisarías como entidades territoriales de la república ${ }^{13}$.

Según Fernando CarRILlo, la Reforma Constitucional de 1968 estuvo dirigida a debilitar la participación del Legislativo en el proceso de planeación, como estrategia para consolidar al presidente como suprema autoridad de la politica económica del país; lo que también ayudó a consolidar el nexo entre planeación y política presupuestal $^{14}$. Esto desvirtuó, en la práctica, la función central que debía tener el Congreso sobre el control financiero y presupuestal del Gobierno, elemento fundamental para la existencia de poderes limitados dentro de una democracia. En 1977, el presidente Alfonso López Michelsen, con el objetivo de otorgar mayor autonomia a las entidades territoriales, planteó la necesidad de realizar una reforma constitucional para reformar el régimen departamental y municipal, y la administración de justicia. Con esto, el Congreso de la República dio trámite al Acto Legislativo 02 de 1977, pero la Corte Suprema de Justicia declaró su inexequibilidad argumentando que el Congreso no podia delegar su facultad constituyente en otro órgano como lo era la Asamblea ${ }^{15}$.

11 Javier Henao Hidron, El poder municipal, op. cit., p. 66.

12 Rodrigo Escobar, "La descentralización y la reforma del Estado, la cultura y la sociedad, la gran tarea de la Colombia de los años ochenta”, en Primer Congreso Nacional de Derecho Administrativo, Medellín, Poligráficas, 1980, p. 301, en Javier Henao Hidron, El poder municipal, op. cit., p. 67.

13 Diego Younes Moreno, Las reformas del Estado y de la administración pública, Bogotá, Temis, 1992, pp. 33-34.

18014 Fernando CARRILlo FlóREz, Constitucionalizar la democracia social. El proceso constituyente de 1991 y América Latina, Bogotá, Hamburg University, University of Oxford, Temis, RedGob, Universidad de Salamanca, SciencesPo, 2011, p. 217.

15 Diego Younes Moreno, Las reformas del Estado y de la administración pública, op. cit., p. 44. 
Posteriormente, con el Decreto 2273 de 1978, el Gobierno del Presidente Julio César Turbay Ayala creó el Consejo Nacional para la Descentralización Administrativa, el cual tenía entre sus principales funciones la de asesorar al presidente de la república en la adopción de medidas para la delegación y desconcentración de funciones destinadas a implantar la descentralización administrativa, mediante la presentación de proyectos de ley o decretos. Así mismo, se determinó que este Consejo debía suministrar asistencia técnica a las entidades participantes y realizar planes de capacitación de funcionarios en entidades territoriales para dar continuidad a los programas de descentralización ${ }^{16}$.

La frustrada reforma de 1979 trató de agregar las nuevas ideas neoliberales imperantes de la época, estableciendo la realización de un Plan Nacional de Desarrollo Económico y Social presentado por el Gobierno y aprobado por el Congreso, que definiría las metas y prioridades de la acción del Estado, de acuerdo con una ley normativa para la concertación de las fuerzas económicas y sociales en los organismos de planeación, y los procedimientos para elaborar el plan ${ }^{17}$.

Para Carrillo, esta propuesta demuestra cómo, a partir de este momento, los sectores público y privado trabajarían en conjunto para el diseño del Plan de Desarrollo Económico y Social desde el centro del país. En desarrollo de la Reforma de 1979, la Ley 38 de 1981 definió las formas de concertación de las fuerzas económicas y sociales en los organismos de planeación y los procedimientos para elaborar el plan. Esta Ley fue declarada exequible por la Corte Suprema de Justicia, el 12 de agosto de 1982, aunque la reforma constitucional de 1979 fuera declarada inexequible ${ }^{18}$.

No obstante lo anterior, en 1979 el informe Wiesner-Bird mostraba que la nación, junto con sus entidades descentralizadas por servicios, acumulaba el 84,6\% de los ingresos del Estado, dejando a los departamentos, intendencias y comisarias con el 9,7\% y a los municipios con el 5,7\%. Adicionalmente, la concentración de los recursos se evidenciaba claramente en el desarrollo de las principales ciudades del país (Bogotá, Medellín y Cali) ${ }^{19}$.

En este contexto, la discusión sobre los planes de desarrollo económico y social del Gobierno, y la consecuente asignación del presupuesto, se realizó al margen del Congreso quien, en principio, representa al pueblo dentro de un sistema de democracia representativa.

Así, no sorprende la falta de atención del Gobierno central a las demandas y necesidades de las regiones, los departamentos y los municipios, a lo largo y ancho del país; dado que muy pocos eran los elegidos por el Gobierno central para participar del proceso de planificación y asignación presupuestal, necesaria para el

16 Ibid., pp. 50-51.

17 Fernando Carrillo Flórez, Constitucionalizar la democracia social..., op. cit., p. 218. Artículo 32 y 80 del Acto Legislativo 1 de 1979.

18 Ibid., pp. 217-219.

19 Javier Henao Hidron, El poder municipal, op. cit., pp. 67-69. 
desarrollo de las comunidades, amplios sectores de la población fueron ignorados por el Estado-nación de la época.

En nuestro concepto, el proceso de descentralización iniciado en la década de los ochenta obedeció, en la teoría, a dar una respuesta efectiva a las comunidades sobre la crisis de legitimidad del Estado, pues gran parte de la población no se sentia representada por el Gobierno nacional. En la práctica, el proceso de descentralización obedeció a una estrategia del Gobierno para formalizar el discurso de la descentralización, retirando con esto presiones politicas indeseadas, sin que existieran políticas o mecanismos efectivos para otorgar mayor poder de decisión o de gestión a las entidades territoriales, en tanto el Gobierno nacional continuaba controlando el proceso de planeación y la mayor parte del presupuesto nacional. Para desarrollar mejor esta idea, a continuación analizaremos cómo se llevó a cabo el proceso de descentralización territorial en Colombia.

\section{LA DESCENTRALIZACIÓN TERRITORIAL EN LA DÉCADA DE LOS OCHENTA}

Como afirmamos, en la década de los ochenta el proceso de descentralización se caracterizó por ser una construcción teórica formulada desde el nivel nacional, sin que existieran politicas efectivas que realmente dieran paso a otorgar mayor poder a las entidades territoriales. Aquí analizaremos algunos aspectos de la descentralización fiscal, política y administrativa de este periodo.

\subsection{La descentralización fiscal}

En 1982, uno de los principales temas discutidos en la campaña presidencial del momento fue la descentralización y el fortalecimiento municipal. Así, durante la presidencia de Belisario Betancur (1982-1986) se expidió la Ley 14 de 1983 que buscó fortalecer los recursos municipales provenientes de los impuestos de industria y comercio, predial y de rodamiento ${ }^{20}$. Por tanto, consideramos que a partir de la promulgación de la mencionada ley se da paso a la descentralización territorial en Colombia de forma continuada, pero, como veremos a continuación, esta ley no fue suficiente, ni efectiva, al tratar de otorgar mayor autonomía a las autoridades locales.

Desde el primer momento del proceso de descentralización territorial eran evidentes las grandes diferencias existentes entre los municipios a lo largo y ancho del país, pero aun así, en esta primera etapa la ley no realizó mayores diferenciaciones entre las entidades territoriales, unificando en la teoria la estructura que debian tener todos los municipios en Colombia, lo que terminó por favorecer a los grandes municipios en detrimento de los medianos y pequeños.

20 Departamento Administrativo de Planeación del Valle (DAPV), Cartilla Descentralización administrativa y autonomía municipal, Cali, DAPV, 1987. 
Debido a la débil estructura institucional de la mayoria de los municipios del país, los alcaldes necesitaron de recursos provenientes de las transferencias de la nación para realizar cualquier actividad u obra pública, y aun con el alivio fiscal de la Ley 14 de 1983, las transferencias efectivamente enviadas a los municipios representaban un porcentaje inferior al ordenado por la ley del situado fiscal de 1971. Los beneficios de las transferencias estuvieron concentrados en los departamentos, las ciudades capitales y el distrito especial, dejando a un lado los municipios más pequeños del país ${ }^{21}$.

En desarrollo de la Ley 14 de 1983, el Gobierno nacional cedió el impuesto de timbre nacional a los departamentos, intendencias, comisarias y al distrito especial de Bogotá. Con relación al impuesto al consumo, reguló a favor de las entidades territoriales la producción, introducción y venta de licores (gravamen que antes era también de la nación). También reguló a favor de los departamentos y del distrito especial los impuestos a los cigarrillos de producción nacional y extranjera y la gasolina motor ${ }^{22}$. Así, el primer paso para el proceso de descentralización territorial fue el traslado de recursos presupuestales de la nación a las diferentes entidades territoriales.

En materia de impuestos municipales, como el impuesto predial, en la práctica se evidenciaba que este representaba muy poco de los ingresos de los municipios, porque no se hacían mayores esfuerzos para mejorar el cobro de dichos impuestos ${ }^{23}$. Así, el proceso de descentralización requería mejorar el sistema de cobro de los impuestos municipales, superando el antiguo sistema en donde el ciudadano era quien preguntaba cuánto debía pagar, y la administración pública municipal no realizaba mayores esfuerzos para mejorar la recaudación de los impuestos dentro de su territorio. Esto sin contar los casos en donde la presencia de grupos armados ilegales impedía el efectivo cobro de estos impuestos.

En la década de los ochenta se requería promover en los municipios la sistematización y modernización de los cobros, además de facilitar al ciudadano la forma de pago, mediante la realización de convenios de los municipios con los bancos. Adicionalmente, se debía promover el pago anticipado del impuesto, evitando las amnistias que premian al moroso y castigan al contribuyente que paga puntualmente sus impuestos.

Un problema adicional en el cobro de los impuestos municipales se presentaba en el avalúo catastral, que era la base del impuesto predial y que se encontraba desactualizado desde épocas anteriores. Esto implicaba que los predios en el país estaban desvalorizados catastralmente. Por tanto, la labor de una entidad nacional, el Instituto Geográfico Agustín Codazzi (IGAC) era fundamental para actualizar los avalúos catastrales y mejorar la base del impuesto predial en todos los municipios del país.

21 Javier Henao Hidron, El poder municipal, op. cit., p. 70.

23 DAPV, Cartilla Descentralización administrativa y autonomía municipal, op. cit. 
Con relación al impuesto de industria y comercio no existía un censo para estos establecimientos y no existían sistemas de cobro modernos en la mayoría de los municipios. Adicionalmente, este impuesto, por su misma naturaleza, benefició en mayor medida a los municipios grandes en donde estaban localizadas la mayoría de las industrias y actividades comerciales, causando grandes desequilibrios entre los grandes y pequeños municipios que no tienen industrias o actividades comerciales relevantes.

Posteriormente, la descentralización fiscal iniciada en 1983 fue complementada con la descentralización administrativa y política, que se estableció mediante el Acto Legislativo 1 de 1986, la Ley 11 del mismo año que establece el nuevo régimen municipal y el Decreto Ley 77 de 1987 o Estatuto de descentralización. A continuación analizaremos los inicios de la descentralización política.

\subsection{La descentralización política}

El Acto Legislativo 1 de 1986, que reformó la Constitución de 1886, permitió a los ciudadanos de los respectivos municipios del país elegir a sus alcaldes por voto popular a partir del segundo domingo de marzo de 1988, para un periodo de dos años. La reforma es de fondo porque anteriormente los alcaldes eran funcionarios de libre nombramiento y remoción, nombrados por los gobernadores, quienes podian trasladarlos permanentemente de un municipio a otro, sin ninguna garantía de estabilidad para el desempeño del cargo. Según estadísticas tomadas para el periodo 1970-1980, el promedio de permanencia de los alcaldes en su cargo era de siete meses (diez meses en ciudades capitales) ${ }^{24}$. En este orden de ideas, el Acto Legislativo 1 de 1986 ayudó a fortalecer la democracia representativa en Colombia en el nivel territorial.

Adicionalmente, las reformas constitucionales y legales implantadas también buscaron promover la democracia participativa, ya que la Ley 11 de 1986 estableció la posibilidad de efectuar consultas populares para decidir sobre asuntos de interés para los habitantes del respectivo municipio, con la finalidad de mejorar los mecanismos de participación ciudadana a nivel municipal.

La Ley 11 de 1986 estableció las bases para la organización y el funcionamiento del municipio, otorgándole autonomía administrativa y permitiendo la participación comunitaria. Esta ley crea las juntas administradoras locales (JAL) a nivel de las comunidades en la zona urbana y, en los corregimientos, en las zonas rurales. Las JAL estaban encargadas de vigilar y controlar la efectiva prestación de los servicios públicos, y de proponer al Consejo Municipal y al alcalde lo que consideraran más conveniente para su jurisdicción, con la finalidad de crear una relación directa entre la comunidad y la administración municipal.

24 IDEM. Javier Henao Hidron, El poder municipal, op. cit., pp. 71-77.

DÍKAION - ISSN 0120-8942 
Las JAL eran elegidas conforme lo determinaran los consejos municipales. Adicionalmente, la Ley 11 de 1986 otorgó a dichos consejos la facultad de elegir al personero y contralor municipal, a los auditores y revisores, y al secretario de la corporación. Por su parte, el tesorero municipal era nombrado y removido por el alcalde municipal ${ }^{25}$.

No obstante lo anterior, según datos del CLAD, a mediados de 1989, solo en 20 municipios se habían creado las JAL y en otros 16 se había acordado o confirmado su constitución ${ }^{26}$. Solo en el 39\% de los municipios colombianos había participación de los usuarios en las juntas directivas de los organismos municipales descentralizados. ${ }^{27}$

De acuerdo con una investigación posterior realizada en 1990, sobre un total de 525 municipios (en febrero de 1990 habia un total de 1.015 en todo el país), solo en 82 municipios, que representan el 15,6\% del total, los consejos municipales habian realizado algún paso en función de dividir el área de su jurisdicción en comunas y corregimientos e instalar las JAL. Únicamente 24 municipios, que representan el 4,95\% afirmaron que las JAL estaban funcionando. A estas cifras hay que agregar Cartagena, Cali, Barranquilla, Pasto, Neiva, Medellín y Armenia, capitales en donde funcionaban las JAL, pero en donde no se aplicó la encuesta ${ }^{28}$.

En este contexto, podemos afirmar que las reformas constitucionales y legales iniciadas en la década de los ochenta ayudaron a establecer formalmente instituciones necesarias para el ejercicio de la democracia representativa y participativa en el nivel territorial, pero estas reformas, impulsadas desde el nivel central de Gobierno, no ayudaron a crear efectivamente una cultura de autogobierno en los ciudadanos o en las corporaciones territoriales, ya que en la práctica no existía una cultura política que lo permitiera y, en consecuencia, pocos municipios utilizaron o implementaron las nuevas instituciones democráticas establecidas en la Ley 11 de 1986.

\subsection{La descentralización administrativa}

La descentralización administrativa realizada en los años ochenta evidencia claramente la estrategia del Gobierno nacional de formalizar el discurso de la descentralización territorial, mediante la expedición de leyes y decretos, retirando con esto presiones politicas indeseadas (ya que de ahora en adelante la competencia

25 Ibid., p. 71.

26 Sonia EuACH, “Las juntas administradoras locales: ¿en qué va este proceso?”, en Curso-taller de actualización en descentralización, planeación y participación comunitaria. Lecturas de apoyo, Bogotá, Asociación Colombiana de Administradores Públicos (ACAP), 1989, en Centro Latinoamericano de Administración para el Desarrollo (CLAD), Experiencias innovadoras en organización y gestión del Estado. Proceso de descentralización y reforma al régimen territorial en Colombia. Reporte de Avances. Centro de Documentación y Análisis de Información (Cedai), Banco de Datos, 1998.

27 Clad, Experiencias innovadoras en organización y gestión del Estado, op. cit.

28 Dario Indalencio RESTREPo Botero, Descentralización y neoliberalismo: balance de un proceso, Santafé de Bogotá, Fondo Editorial CEIR- Realidad Municipal, en Clad, Experiencias innovadoras en organización y gestión del Estado, op. cit. 
se encuentra en cabeza de las autoridades locales y no del Gobierno nacional), sin que en la práctica fuera factible para las autoridades locales tener mayor poder de decisión o de gestión, ya que, como veremos a continuación, la cantidad de competencias trasladadas impidió desde el inicio una efectiva y responsable descentralización territorial.

Primero debemos referirnos al traslado de competencias y funciones de la nación a los territorios, realizada mediante la Ley 12 de 1986, que definió la lista de sectores en los cuales se debían invertir los recursos, ordenando también el traspaso de servicios y funciones de entidades del orden nacional a los municipios, y ordenando la supresión de las entidades o dependencias nacionales (cuyas funciones fueron traspasadas a las entidades locales). Para el desarrollo de los anteriores mandatos, la Ley 12 de 1986 otorgó facultades extraordinarias al presidente de la república, y en uso de estas facultades, el Gobierno nacional expidió los decretos 77, 78, 80 y 81 de 1987.

El Decreto extraordinario 77 de 1987 estableció el estatuto de la descentralización a favor de los municipios y transfirió desde el nivel central la responsabilidad por la prestación de los servicios públicos, determinando también que los municipios debían tener un plan quinquenal de inversión. Los sectores que fueron transferidos fueron los siguientes (tabla 1):

\section{Tabla 1. Funciones trasladadas a los municipios}

\begin{tabular}{|c|l|}
\hline Sector & \multicolumn{1}{c|}{ Funciones trasladadas } \\
\hline $\begin{array}{c}\text { Agua potable y } \\
\text { saneamiento ambiental }\end{array}$ & $\begin{array}{l}\text { Prestación de servicios públicos como: acueducto, saneamiento } \\
\text { ambiental, alcantarillado, mataderos, aseo, plaza de mercado. }\end{array}$ \\
\hline Salud & $\begin{array}{l}\text { Construcción de obras civiles, dotación básica, mantenimiento integral } \\
\text { de centros y puestos de salud, hospitales locales y ancianatos. }\end{array}$ \\
\hline Educación & $\begin{array}{l}\text { Construcción, dotación y mantenimiento de planteles escolares, } \\
\text { instalaciones deportivas, de educación física y recreación. }\end{array}$ \\
\hline Agropecuario & $\begin{array}{l}\text { Prestación de servicios de asistencia técnica a pequeños productores; } \\
\text { ejecución de programas de seguridad alimentaria y de provisión de } \\
\text { alimentos básicos. }\end{array}$ \\
\hline Desarrollo urbano & $\begin{array}{l}\text { Adecuación de terrenos con infraestructura vial y de servicios públicos y } \\
\text { comunales; construcción de infraestructura matriz o principal de servicios } \\
\text { públicos y provisión de equipamiento social; programas de vivienda y } \\
\text { urbanismo. }\end{array}$ \\
\hline Obras públicas & $\begin{array}{l}\text { Administración y mantenimiento de parques urbanos y monumentos } \\
\text { nacionales; construcción, conservación, operación y mantenimiento } \\
\text { de puertos y muelles fluviales; financiamiento de proyectos de } \\
\text { construcción, conservación y mejoramiento de caminos vecinales. }\end{array}$ \\
\hline
\end{tabular}

186 Fuente: CLAD, Experiencias innovadoras en organización y gestión del Estado. Proceso de descentralización y reforma al régimen territorial en Colombia. Reporte de Avances. Centro de Documentación y Análisis de Información (Cedai), Banco de Datos, 1998. 
De esta forma, la nación transfirió a los municipios de un momento para otro todas las competencias que por un siglo estuvieron concentradas en el Gobierno nacional, sin que existieran planes de ajuste o un periodo de transición para que estos conocieran y se prepararan para asumir las nuevas obligaciones, conforme a las modificaciones realizadas dentro de la estructura del Estado. Adicionalmente, la ley no realizó ninguna diferenciación entre los municipios en razón de su tamaño, número de habitantes, recursos, situación geográfica o cualquier otro factor.

A fin de ilustrar un poco las dificultades que tuvieron los municipios para implementar en la práctica la transferencia de funciones y competencias de la nación, la cartilla instructiva del Departamento Administrativo de Planeación del Valle $(\mathrm{DAPV})^{29}$, elaborada para ilustrar a las autoridades locales sobre las nuevas funciones en los municipios, establecía que las autoridades municipales debían realizar de forma inmediata las siguientes actividades:

a. Crear una oficina de planeación municipal y conformar una junta asesora de planeación municipal.

b. Crear una unidad de asistencia agropecuaria.

c. Adecuar la estructura administrativa municipal a las nuevas normas de descentralización.

d. Sistematizar el cobro de los impuestos, especialmente el predial, industria y comercio y de rodamiento.

e. Suscribir acuerdo con el IGAC para la actualización cartográfica y predial del respectivo municipio.

f. Elaborar un censo actualizado de establecimientos industriales o comerciales para efectos del cobro del impuesto.

g. Organizar a las comunidades en comunas en el área urbana del municipio y en corregimientos en el área rural.

h. Conformar las juntas administradoras locales en cada una de las comunas o corregimientos.

i. Crear entes especializados para el adecuado manejo de los servicios públicos o celebración de convenios con entidades supramunicipales especializados en la prestación de los mismos.

j. Celebrar convenios con el Instituto Colombiano Agropecuario (ICA), la Corporación Autónoma Regional del Valle (CVC), la Secretaría de Agricultura, el Programa de Desarrollo Rural Integrado (DRI) para la prestación de servicios agropecuarios.

29 DAPV, Cartilla Descentralización administrativa y autonomía municipal, op. cit. 
k. Elaborar el presupuesto municipal por programas y proyectos.

1. Elaborar planes o programas de inversión municipal para periodos de tres o cinco años.

Evidentemente, implementar de un momento para otro funciones para el desarrollo de sectores tan complejos y variados como agua potable y saneamiento ambiental, salud, educación, agropecuario, desarrollo urbano y obras públicas, sin mayores recursos, infraestructura o personal capacitado, era una fórmula certera para el colapso de las administraciones públicas municipales, especialmente en los pequeños y medianos municipios del país.

\section{TRANSFORMACIONES EN LA ESTRUCTURA DE LA NACIÓN EN LA DÉCADA DE LOS OCHENTA}

En el nivel nacional, la nueva organización del Estado obligó a liquidar y reestructurar entidades, conforme los nuevos lineamientos establecidos por el Gobierno nacional, en cada uno de los sectores donde fueron trasladadas las funciones a los municipios. Aquí realizaremos en breve recuento por sector de las modificaciones más relevantes realizadas a partir de 1987.

En el sector de agua potable y saneamiento ambiental se ordenó la liquidación del Instituto de Fomento Municipal (Insfopal), que debió terminar el 31 de diciembre de 1989, y se ordenó la supresión de la División de Saneamiento Básico del Ministerio de Salud. En el sector salud, se ordenó la supresión de algunas funciones del Fondo Nacional Hospitalario, y la adición de funciones al Instituto Colombiano de Bienestar Familiar (ICBF). En el sector de educación se suprimieron funciones de Coldeportes y se ordenó la liquidación del Instituto Colombiano de Construcciones Escolares (ICCE) ${ }^{30}$.

En el sector agropecuario, se asignó a los municipios el servicio de asistencia técnica agropecuaria directa a pequeños productores, los cuales fueron desarrollados por el ICA y el Instituto Colombiano de la Reforma Agraria (Incora). Para facilitar la adjudicación de tierras baldías se facultó al Incora para delegar en los municipios la función de levantar con sus recursos los informes necesarios para la adjudicación ordinaria de baldios nacionales. Se definió la participación de comunidades rurales en los programas nacionales del Fondo DRI, por medio de comités veredales, municipales, distritales y departamentales ${ }^{31}$.

De otro lado, se atribuyó al Ministerio de Desarrollo la competencia para dirigir la política de desarrollo urbano y vigilar su aplicación. En el sector de obras públicas, el Fondo Nacional de Caminos Vecinales se convirtió en una entidad cofi-

30 Diego Younes Moreno, Curso de Derecho Administrativo, Bogotá, Temis, 1997, pp. 23-24.

31 Ibid., p. 25. 
nanciadora de los municipios, las asociaciones de municipios, las intendencias, los departamentos y las comisarias ${ }^{32}$.

De esta forma podemos concluir que los primeros años de descentralización territorial en Colombia no ayudaron al fortalecimiento institucional de los municipios, los departamentos o la nación, ya que el traspaso de competencias y recursos de la nación a las entidades territoriales se desarrolló de manera inmediata, por orden legal, sin que existieran planes, programas o periodos de transición que permitieran el traspaso responsable de las competencias y los recursos a las entidades territoriales, lo cual se vio agravado al verificar la inexistencia de una cultura democrática o de autogobierno en las entidades territoriales, que históricamente debieron acatar las decisiones impartidas desde el Gobierno central, con ayuda de entidades nacionales especializadas en cada uno de los sectores de actuación. En este orden de ideas, no sorprenden los pobres resultados del proceso de descentralización territorial en Colombia en los primeros años de implementación, ya que en el país no existian buenas condiciones políticas, institucionales o culturales para el buen desarrollo de la autonomía territorial de forma coordinada con el nivel central del Gobierno.

\section{PRINCIPALES CARACTERÍSTICAS DE LA DESCENTRALIZACIÓN TERRITORIAL EN COLOMBIA}

En la década de los ochenta, el traspaso automático de funciones y competencias a las entidades territoriales, junto a la reestructuración de entidades nacionales, imposibilitó el transferencia efectiva y responsable de las funciones del orden nacional al orden territorial, causando que muchas funciones del Estado fueran incumplidas por los municipios que no tenían capacidad de ejecución. En otros casos, el Gobierno nacional tuvo que asumir nuevamente muchas de las funciones que antes habian sido entregadas a municipios y departamentos para su efectiva ejecución.

En este orden de ideas, el Gobierno nacional continuó ejerciendo funciones esenciales para el desarrollo de las entidades territoriales, las cuales condicionaban de forma importante el avance de proyectos, programas y políticas en el nivel territorial. Así las cosas, el buen desempeño de la nación condicionó de forma importante el éxito o fracaso de la gestión en el nivel territorial.

Teniendo en cuenta lo anterior, en términos generales, podemos identificar cuatro características relevantes del proceso de descentralización en Colombia en la década de los años ochenta.

La primera característica determina que, en teoría (debido a la transferencia de competencias de la nación a los municipios), el municipio comienza a configurarse como la entidad fundamental de la división política administrativa del Estado, ya que a él le corresponde prestar los servicios públicos que determine la ley,

32 Ibid., p. 26. 
construir las obras públicas que demande el proceso local, ordenar el desarrollo del territorio, promover la participación comunitaria, el mejoramiento social y cultural de los habitantes y cumplir con las demás funciones que le asignen la Constitución y las leyes.

Aun así, en la práctica se evidencia que en cada sector de Gobierno existen diferentes normas nacionales que condicionan de forma importante la autonomía del municipio, que debe actuar de manera coordinada con la nación y otros entes territoriales conforme lo determinen la Constitución y las leyes. Por tanto, la gestión de los asuntos públicos del municipio depende de la eficacia y la coordinación de diferentes entidades públicas en distintos niveles de gobierno.

La segunda característica trata sobre la existencia de tres áreas principales de descentralización, que se han desarrollado a partir de los años ochenta, las cuales son: la descentralización política, la descentralización administrativa-institucional y la descentralización fiscal o económico-financiera ${ }^{33}$. Al respecto, un informe del Centro Latinoamericano de Administración para el Desarrollo (CLAD) resalta las características de estas tres áreas, así:

- Descentralización económico-financiera o fiscal: es la autonomía que tienen las entidades territoriales para tomar decisiones respecto a sus finanzas, tanto en términos de ingresos como de asignación de gastos. Este tipo de descentralización se manifiesta en:

- Transferencia de recursos a los municipios y otras entidades territoriales desde la nación.

- Financiamiento del desarrollo y de la inversión territorial.

- Creación de recursos propios por parte de los municipios y otras entidades territoriales.

- Descentralización administrativa-institucional: comprende el traslado de competencias o funciones a las entidades territoriales. Este tipo de descentralización se manifiesta en:

- Transferencia de competencias a los municipios y otras entidades territoriales mediante leyes y decretos nacionales.

- Transformaciones en el Poder Ejecutivo nacional en función de la descentralización mediante leyes y decretos nacionales.

- Reorganización de los departamentos y los municipios para asumir las nuevas competencias y funciones.

33 CLAD, Experiencias innovadoras en organización y gestión del Estado, op. cit. 
- Necesidad de fortalecimiento técnico de la gestión municipal.

- Establecimiento de mecanismos para mejorar la coordinación entre las entidades en los diferentes niveles de gobierno.

- Descentralización politica: hace referencia al mayor grado de participación de la comunidad y de autonomía de las entidades territoriales en la toma de decisiones públicas que afectan los territorios. Este tipo de descentralización se manifiesta en:

- Elección popular y directa de alcalde municipal.

- Creación de mecanismos de participación ciudadana a nivel municipal.

- Elección directa de los gobernadores de departamentos.

- Nueva composición y funciones de los consejos municipales y asambleas departamentales.

- Moralización de las entidades territoriales mediante la expedición de diversas leyes y decretos que reglamentan su actuación.

En desarrollo de lo anterior, la tercera característica trata sobre cómo la descentralización en Colombia se ha desarrollado mediante la expedición de un conjunto importante de instrumentos normativos (leyes, decretos, ordenanzas, reglamentos, etc.) que apoyan y conforman el marco jurídico de la descentralización, de forma tal que esta se ha realizado desde la nación hacia los municipios, sin tener en cuenta las particularidades propias de cada municipio, tales como nivel de desarrollo, número de habitantes, localización, industria y comercio, etc.

Por tanto, la descentralización no ha sido producto del aumento de las capacidades de autogobierno de los municipios, y tampoco se ha caracterizado por el fortalecimiento de las capacidades politicas de los ciudadanos. La autonomía territorial en Colombia se ha construido de arriba hacia abajo. Esto genera que la nación pueda reformar la Constitución y las leyes para limitar la descentralización y recentralizar el poder en la nación, debido en parte a las pocas capacidades de autogobierno que muestran las entidades territoriales y a su necesidad de apoyo desde el nivel nacional.

Una cuarta característica destaca la necesidad de transferencia de recursos de la nación a las entidades territoriales, debido principalmente a la poca capacidad de estas para gestionar sus propios recursos. Aquí se debe resaltar que la transferencia automática de recursos a las entidades territoriales no estuvo (en todos los casos) acompañada de estrategias o programas que ayudaran a construir capacidades técnicas y de gestión para el apropiado manejo de los recursos, causando profundas dificultades en la administración de los recursos y en el reparto de las competencias entre los diferentes niveles de gobierno. 
Estas cuatro características evidencian la existencia de una fuerte cultura centralista, la cual fue incorporada en la Constitución de 1991. Según Estupiñán,

"...la constante centralista y el modelo de Estado unitario estuvieron presentes y triunfantes, tanto en el preludio como en el interior de la Asamblea Nacional Constituyente de 1991. Los actores, comisiones, debates políticos y académicos formularon un modelo relativamente anclado en las lógicas territoriales constitucionales de 1886 pero aderezado con nuevos principios ${ }^{34 "}$.

De esta forma, la estructura de Estado unitario, descentralizado, fue una tendencia mayoritaria en la Asamblea Nacional Constituyente, que se reflejó claramente en la Constitución de 1991, aunque también, de forma paralela, se establecieran nuevos mecanismos para garantizar a los municipios más autonomía y recursos.

\section{CONCLUSIONES}

Históricamente Colombia se ha caracterizado por la centralización del poder en cabeza del Gobierno nacional, y solo en la década de los ochenta el Estado comenzó un proceso serio de descentralización del poder en las entidades territoriales. Así, luego de un siglo de instituciones, prácticas y costumbres que favorecían la centralización del poder en el Gobierno nacional, se inició un proceso de institucionalización de estructuras y prácticas que descentralizan el poder en las entidades territoriales, proceso que no ha estado exento de obstáculos y malos entendidos, en parte debido a que las costumbres centralistas y la estructura del Estado colombiano no permitian, en la práctica, otorgar mayor autonomía a las entidades territoriales.

La descentralización en la década de los ochenta se quiso hacer de manera automática mediante la expedición de leyes que debían ser obedecidas por los funcionarios públicos, sin que existiera preocupación alguna por la creación de estructuras apropiadas para el desarrollo responsable de las funciones asignadas. Tampoco se tuvo en cuenta la importancia de capacitar y entrenar a los funcionarios públicos y a los ciudadanos en la creación de competencias y habilidades apropiadas para la autogestión y el autogobierno de los asuntos más importantes en las entidades territoriales.

En este orden de ideas, consideramos que comprender las deficiencias que ha tenido desde el inicio el proceso de descentralización territorial en Colombia, nos ayuda a evidenciar que el marco normativo que transfiere competencias y otorga autonomía a las entidades territoriales no es suficiente, si esto no se acompaña de reformas institucionales responsables y programas de capacitación y entrenamiento que permitan fortalecer las capacidades de autogobierno a largo plazo

34 Liliana Estupiñán Achury, "El ordenamiento territorial en la Asamblea Nacional Constituyente de 1991. Lectura socio-jurídica desde el nivel intermedio de gobierno”, en Opinión Jurídica 11-21 (2012), pp. 19-37. 
de las entidades territoriales y las capacidades de comunicación, cooperación y coordinación entre funcionarios y entidades en diferentes niveles de gobierno.

Para que las prácticas de autogobierno se consoliden en las entidades territoriales, creemos que es fundamental, por un lado, fortalecer la información disponible sobre las particularidades propias de cada entidad territorial y, por otro lado, fortalecer todas las entidades públicas implicadas en el proceso de descentralización (en todos los niveles de gobierno), mediante la implementación de procesos de capacitación y de sistemas de información transversales que ayuden a mejorar la comunicación, cooperación y coordinación entre las distintas entidades y niveles de gobierno. Consideramos que treinta años después de iniciado el proceso de descentralización territorial en Colombia, todavia falta por corregir muchos de los errores iniciales que se presentaron desde la década de los ochenta.

\section{BIBLIOGRAFÍA}

Cabrero Mendoza, E., La nueva gestión municipal en México: análisis de experiencias innovadoras en gobiernos locales, México, CIDE, 1995.

Caminal, Miguel, "Nacionalismo y federalismo", en Joan Antón Mellón (ed.), Ideologías y movimientos políticos contemporáneos, Madrid, Tecnos, 1998.

CÁrdenas, Mauricio, Carolina Mejía, Mauricio Olivera, La economía política del proceso presupuestal: el caso de Colombia, Bogotá, BID-Fedesarrollo, 2007, en http://idbdocs.iadb.org/wsdocs/getdocument.aspx?docnum=1161524. Fecha de Consulta: 17 de septiembre de 2012.

CARrillo Flórez, Fernando, Constitucionalizar la democracia social. El proceso constituyente de 1991 y América Latina, Bogotá, Hamburg University, University of Oxford, Temis, RedGob, Universidad de Salamanca, SciencesPo, 2011, p. 217.

CAstells, Manuel, La era de la información. Economía sociedad y cultura, vol. II. El poder de la identidad, 5 ed., México, Siglo XXI Editores, trad. Carmen Martínez Gimeno, 2004, p. 301.

Departamento Administrativo de Planeación del Valle (DAPV), Cartilla Descentralización administrativa y autonomía municipal, Cali, DAPV, 1987.

ELACH, Sonia, “Las juntas administradoras locales: ¿en qué va este proceso?”, en Curso-taller de actualización en descentralización, planeación y participación comunitaria. Lecturas de apoyo, Bogotá, Asociación Colombiana de Administradores Públicos (ACAP), 1989.

EscoBAR, Rodrigo, "La descentralización y la reforma del Estado, la cultura y la sociedad, la gran tarea de la Colombia de los años ochenta”, en Primer Congreso Nacional de Derecho Administrativo, Medellin, Poligráficas, 1980.

EstupiñÁn AchurY, Liliana, "El ordenamiento territorial en la Asamblea Nacional Constituyente de 1991. Lectura socio-jurídica desde el nivel intermedio de gobierno", en Opinión Jurídica 11-21 (2012), pp. 19-37. 
Falleti, T. G., Decentralization and subnational politics in Latin America, New York, Cambridge University Press, 2010.

Finot, I., Descentralización en América Latina: Teoría y práctica, Santiago de Chile, Cepal, 2001.

FioRAVANTI, Maurizio, Los derechos fundamentales: apuntes de historia de las constituciones, Madrid, Trotta, 2007, pp. 104-105.

Guindle, M., Going Local. Decentralization, democratization and the promise of good governance, Princeton, Pricenton University Press, 2007.

Henao Hidron, Javier, El poder municipal, 16 ed., Medellín, Biblioteca Jurídica, 2013.

Hernández-Bonivento, José A. Instituciones informales y reforma del Estado: análisis al proceso de descentralización en Colombia, Madrid, GIGAPP Estudios/ Working Papers, 2012.

KuRE, Ileana, "Descentralización: retos para su consolidación”, en Revista de Planeación y Desarrollo 26-2 (1995), pp. 89-129.

Lindert, P. y O. VerKoren, Decentralized development in Latin America: experiences in local governance and local development, New York, Springer, 2010.

RESTREPo Botero, Dario Indalencio, Descentralización y neoliberalismo: balance de un proceso, Santafé de Bogotá, Fondo Editorial CEIR- Realidad Municipal, 1998.

Rodríguez Peñaranda, María Luisa, Minorías, acción pública de inconstitucionalidad y democracia deliberativa, Bogotá, Universidad Externado de Colombia, 2005.

Salvador Crespo, M., "El fortalecimiento institucional de los municipios", en Castillo Blanco, Análisis de los procesos de descentralización en América Latina: balances y perspectivas, Granada, Unión Iberoamericana de Municipalistas, 2008.

Valencia Tello, Diana Carolina, El Estado en la Era de la Globalización y las Nuevas Tecnologías. Tesis de Doctorado, Universidad Federal del Paraná, Brasil, 2013.

Younes Moreno, Diego, Las reformas del Estado y de la administración pública, Bogotá, Temis, 1992. 